\title{
Spontaneous Pneumomediastinum and Subcutaneous Emphysema: A Two Cases Reports
}

\author{
Selma Abdala*, Salma Aitbatahar, Lamyae Amro
}

Faculty of Medicine and Pharmacy, Cadi Ayyad University, Department of Pneumology, ARRAZI Hospital, Mohamed VI University Hospital Center, Marrakech, Morocco

DOI: $10.36347 /$ simcr.2021.v09i01.005

| Received: 21.12.2020 | Accepted: 05.01.2021 | Published: 09.01.2021

*Corresponding author: Selma Abdala

\section{Abstract}

Spontaneous pneumomediastinum (SPM) is an uncommon, mostly benign disorder that usually occurs in young adult males without any apparent pre-existing factor or disease. SPM responds extremely well to conservative treatment, without recurrence in the great majority of cases. We report two cases of SPM and pneumothorax in two young males following a forceful vomiting and a bout of sudden coughing with no underlying lung lesion.

Keywords: Coughing, vomiting, spontaneous pneumomediastinum, subcutaneous emphysema, pneumothorax.

Copyright $\odot 2021$ The Author(s): This is an open-access article distributed under the terms of the Creative Commons Attribution 4.0 International License (CC BY-NC 4.0) which permits unrestricted use, distribution, and reproduction in any medium for non-commercial use provided the original author and source are credited.

\section{INTRODUCTION}

Pneumomediastinum is the presence of air in the mediastinum, it is considered as secondary when a causative factor is identified. Spontaneous pneumomediastinum (SPM) is a rare condition which occurs in the absence of pulmonary disease or any other inducing factors $[1,2]$. We report two cases of SPM and pneumothorax in two young males following a forceful vomiting and a bout of sudden coughing with no underlying lung lesion.

\section{CASE REPORTS}

\section{Case 1}

A 41-year-old man, working as a builder and nonsmoker but exposed to second hand smoke for 20 years at work presented to the emergency department with a 4-day history of spastic cough due to a cold. He had no known allergies and no history of pulmonary or cardiovascular disease. He had a consultation at a private practice at the beginning of his cold and was given oral antibiotics (macrolide) and aspirin. One hour after taking his medicine, he developed chest pain, dyspnea and swelling of the face, neck and upper chest.

At his admission, the patient presented with respiratory distress syndrome so he was immediately transferred to the intensive care unit of the emergency department and put under oxygen masque. On physical examination, crackling-feel was noted in the neck, the clavicular areas, and upper chest. Pulmonary and cardiac auscultations were normal.
The chest X-ray on admission showed a large subcutaneous emphysema and pneumomediastinum (Figure-1). The computed tomography revealed a pneumomediastinum, subcutaneous emphysema and bilateral pneumothorax (Figure-2). The lungs were otherwise clear.

The patient was given nasal oxygen and codeine for the pain. He was kept for close observation in the hospital during the next 2 days. The subcutaneous emphysema improved clinically and the chest X-ray after 2 days showed significant resolution of the emphysema and pneumomediastium (Figure-3).

Case-2

29-year-old patient admitted to emergency department for vomiting secondary to diabetic ketoacidosis complicating his type 1 diabetes. The physical examination revealed subcutaneous emphysema and epigastric tenderness, urine test strips shows three glucose crosses and two acetone crosses, the blood bicarbonates level was $12 \mathrm{mmol} / \mathrm{l}$. The chest radiograph showed a large subcutaneous emphysema and pneumomediastinum. The CT scan of chest revealed a right pneumothorax, a pneumomediastinum with subcutaneous emphysema extending to the lower neck (Figure-4). Intravenous fluid perfusion and insulin were administered in order to treat the acidocetosis; as well as nasal oxygen which was given to help resolve the pneumothorax. After glycemia control and conservative treatement of the pneumothorax and pneumomediatinum, the patient was discharged. The 


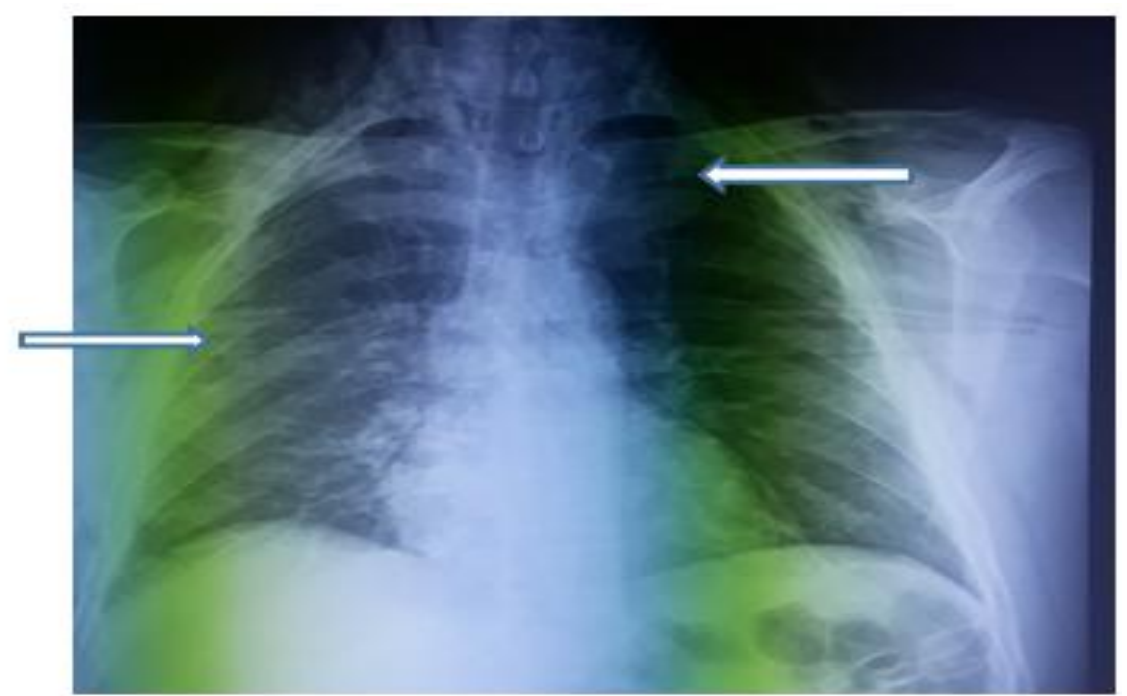

Fig-1: Chest $X$ ray showing pneumomediastinum, and subcutaneous emphysema

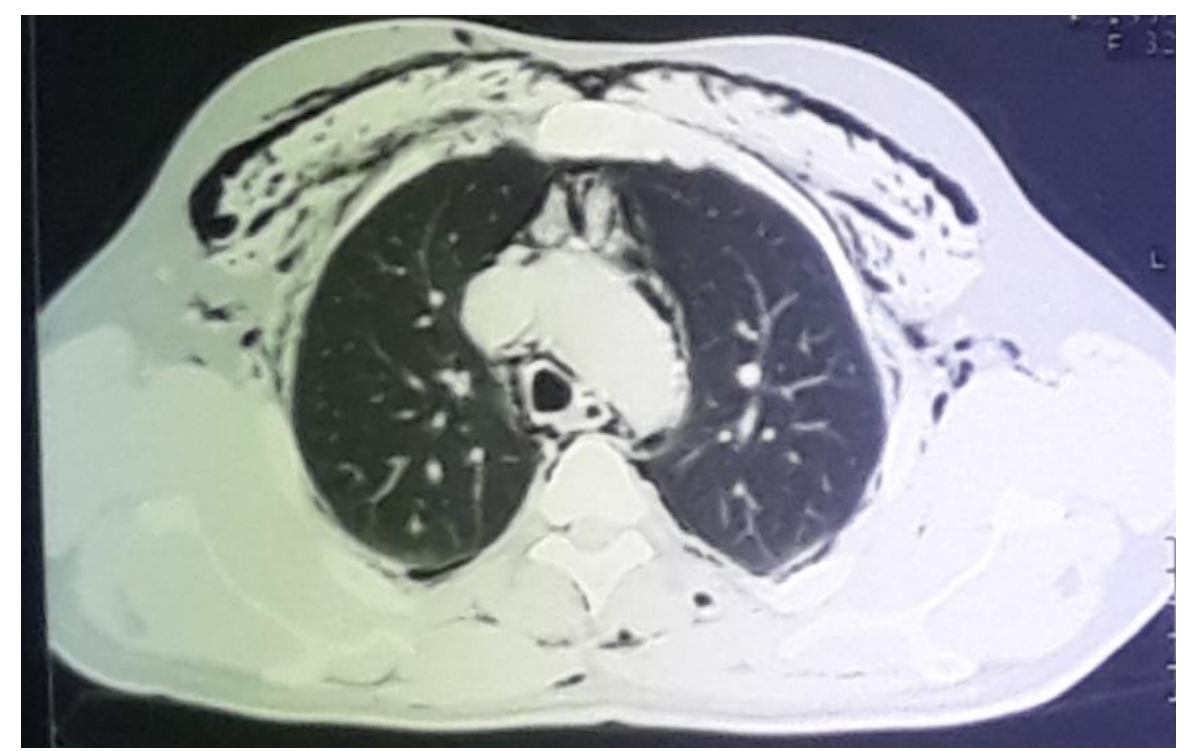

Fig-2: Section 1-computed tomography (thorax) revealing apneumomediastinum with subcutaneous emphysema and bilateral pneumothorax

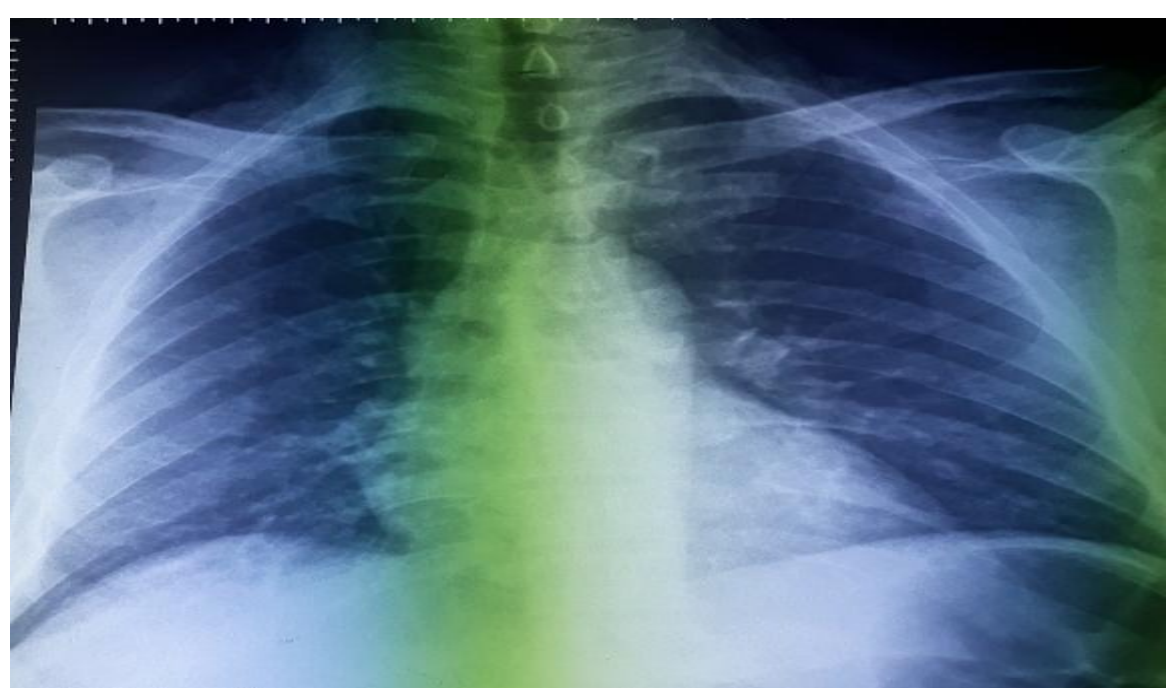

Fig-3: Chest X-ray after 2 days showing a significant resolution of the emphysema and pneumomediastium 


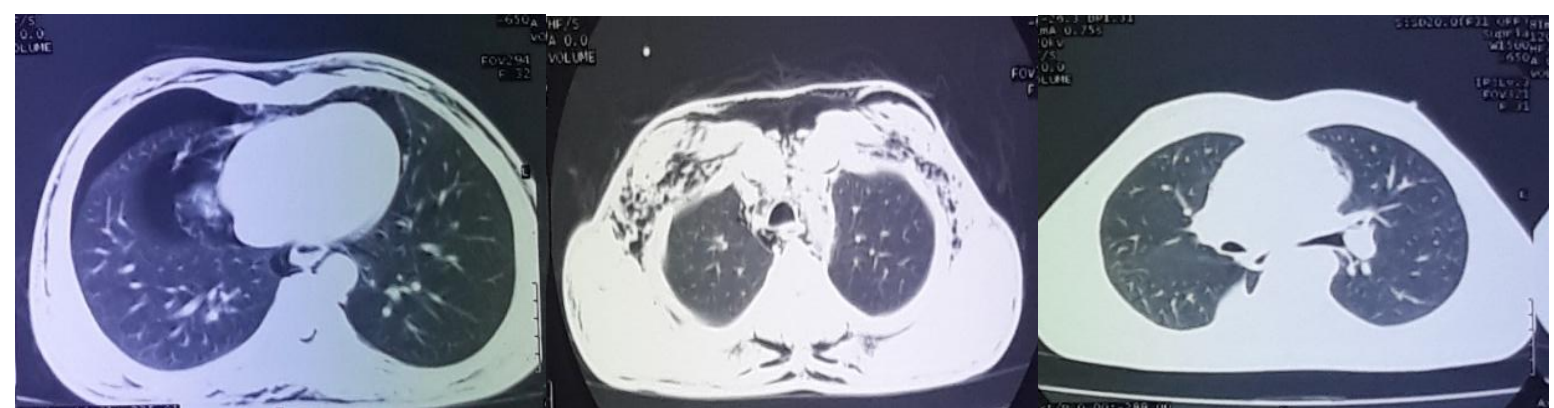

Fig-4: Computed tomography scan of the chest showing air in the soft tissues of the neck and within the anterior mediastinum and right pneumothorax (A), at the left CT scan showing a significant resolution of the emphysema, penomothorax and pneumomediastium

\section{DISCUSSION}

The mediastinal cavity is defined as the area demarcated by the pleural cavities laterally, the cervicothoracic inlet as an upper limit and the diaphragm as an inferior one [3]. Pneumomediastinum (PM) also referred to as mediastinal emphysema was originally described in 1819 by Laënnec [4, 5] and is defined as the presence of free air in the mediastinal cavity. The discovery of free air in the mediastinal cavity is often thought of as a phenomenon secondary to a more serious medical condition. PM is broken down into two categories: the first one is as a result of trauma or caused iatrogenic ally due to endoscopic or other therapeutic procedures. Such cases are referred to as secondary PM and have a clear causative factor. The second one is the presence of free air in the mediastinal cavity without a clear etiology, which is referred to as spontaneous pneumomediastinum (SPM). It is a rare condition, reported with incidence of less than 1/44000, and often has a benign outcome [6].

Cough is an explosive expiration which is a physiological protective mechanism allowing the clearing of the trachea and bronchi from secretions and foreign material. However, the sudden increase in intrathoracic pressure during coughing is a risk factor of alveolar over distension and rupture. The forceful contraction of expiratory muscles limits the expansion of lungs to their total lung capacity by splinting the chest wall and thus usually preventing any volutrauma that may occur and causes alveolar volume disruption of alveolar walls [7]. Rarely, the transient increase in intrapulmonarypressure during coughing may also cause alveolar rupture.Coughing is usually uneventful, but occasionally results in microscopic alveolar ruptures [6].

SPM usually follows vomiting, intense exertion, and Valsalva maneuvers, all of which cause sudden increase in intra-alveolar pressure without specific cause such as trauma. Studies have also reported its association with cocaine and marijuana use and asthma attacks [8, 9]. Cough has also been suggested as a possible cause of pneumomediastinum $[8,10]$. In this reported case, cough was the only etiology found justifying the occurrence of bilateral spontaneous pneumothorax, pneumomediastinum and subcutaneous emphysema in a otherwise healthy young man with no known respiratory condition. No obvious preceding events or factors are detectedin nearly $20 \%$ of all mediastinal emphysema patients [8].

Chest and neck pain, dyspnea, subcutaneous emphysema, hypotension, dysphagia, and cough arecommon symptoms of SPM. Chest pain is characteristically sudden and of pleuritic type, and may radiate to the backand shoulders. Subcutaneous emphysema has a prevalenceranging from $40 \%$ to $100 \%$ [7] and occurs when intrathoracic air leaks into the soft tissues after pneumothorax or pneumomediastinum. Hamman's sign is another clinical finding of SPM and was described by Hamman as the crunching, rasping sound, synchronous with the heartbeat during auscultation.

There is no consensus on the method of diagnosis of SPM [11]. While some authors report that simple chest X-ray alone is enough for the diagnostic $[12,13]$, others state that chest X-ray is sufficient for the diagnosis of SPM if a patient did not have preceding trauma, foreign body inhalation or vomiting, and that further investigations are not required if the patient is stable [14]. On the other hand, some authors suggested that all patients should under go chest CT to diagnose SPM in order to investigate any other underlying conditions [9]. It is also recommended that chest X-ray is the initial method of diagnosis, but chest CT and other investigations should be performed if SPM and other conditions are suspected $[15,16]$.

Primary SPM is retained after all other causes of mediastinal emphysema are excluded and can be treated easily. However, this condition may lead to severe complications such as tension pneumomediastinum that can be fatal and occurs in case of increased mediastinal pressure. Once the diagnosis of SPM is established, the patient has to be hospitalized for a minimum of 24 hours observation to prevent potential complications which may require a surgical intervention [8]. Treatment includes bed rest, analgesic and oxygen administration, mediastinal emphysema usually resolves within several days. 


\section{CONCLUSiON}

In this article we described two cases of spontaneous pneumomediastinum, subcutaneous emphysema and pneumothorax that were induced by coughing or vomiting. The occurrence of the swelling right after the intake of antibiotics and aspirin as well as the respiratory distress could have induced a false diagnosis of an allergy. Also the incidence of chest pain complaints is lower in cases of pneumomediastinum accompanied by DKA than in cases of generalized pneumomediastinum, and dyspnea can be regarded as a symptom of DKA; this increases the chances of missing the correct diagnosis, however, life-threatening complications (pneumothorax, pneumopericardium, and mediastinitis) might accompany this condition. Therefore, clinicians need to include this complication in the differential diagnosis. The diagnosis of SPM was achieved thanks to a through physical examination and the immediately performed chest $\mathrm{X}$ ray. The follow up was favorable and the patients recovered spontaneously without any complications.

\section{REFERENCES}

1. Macklin MT, Macklin CC. Malignant interstitial emphysema of the lungs and mediastinum as an important occult complication in many respiratory diseases and other conditions: interpretation of the clinical literature in the light of laboratory experiment. Medicine (Baltimore). 1944; 23:281358.

2. Sakai M, Murayama S, Gibo M, Akamine T, Nagata O. Frequent cause of the Macklin effect in spontaneous pneumomediastinum: demonstration by multidetector-row computed tomography. J Comput Assist Tomogr. 2006; 30:92-4.

3. Fraser RS, Pare JA, Fraser RG, Pare PD. The normal chest. Synopsis of Diseases of the Chest. 2nd ed. Philadelphia, PA: WB Saunders; 1994; 1116.

4. Laënnec RT. De L'auscultation Médiate ou Traité du Diagnostic des Maladies des Poumon et du Coeur. 1st ed. Paris: Brosson\&Chaudé; 1819.

5. Roguin A. Rene theophilehyacinthelaënnec (17811826): The man behind the stethoscope. Clin Med Res. 2006; 4:230-5.
6. Macia I, Moya J, Ramos R, Morera R, Escobar I, Saumench J. Spontaneous pneumomediastinum: 41 cases. Eur J Cardiothorac Surg. 2007; 31:11104.

7. Pierson DJ. Alveolar rupture during mechanical ventilation: Role of PEEP, peak airway pressure and distending volume. Respir Care. 1988; 33:472-83.

8. Weissberg D, Weissberg D. Spontaneous mediastinal emphysema. Eur J Cardiothorac Surg. 2004; 26:885-8.

9. Koullias GJ, Korkolis DP, Wang XJ, Hammond GL. Current assessment and management of spontaneous pneumomediastinum: experience in 24 adult patients. Eur J Cardiothorac Surg. 2004; 25:852-5.

10. Rose WD, Veach JS, Tehranzdeh J. Spontaneous pneumomediastinum as a cause of neck pain, dysphagia and chest pain. Arch Intern Med. 1984; 144:392-3.

11. Lee SC, Lee DH, Kim GJ. Is primary spontaneous pneumomediastinum a truly benign entity? Emerg Med Australas. 2014; 26:573-8.

12. Campillo-Soto A, Coll-Salinas A, Soria-Aledo V, Blanco-Barrio A, Flores-Pastor B, Candel-arenas $\mathrm{M}$, et al. Spontaneous pneumomediastinum: descriptive study of our experience with 36 cases. Arch Bronconeumol. 2005; 41:528-31.

13. Freixinet J, Garcia F, Rodriguez PM, Santana NB, Quintero CO, Hussein M. Spontaneous pneumomediastinum long-term follow-up. Respir Med. 2005; 99:1160-3.

14. Esayag Y, Furer V, Izbicki G. Spontaneous pneumomediastinum: is a chest X-ray enough? A single-center case series. Isr Med Assoc J. 2008; 10:575-8.

15. Takada K, Matsumoto S, Hiramatsu T, Kojima E, Watanabe H, Sizu Ml. Management of spontaneous pneumomediastinum based on clinical experience of 25 cases. Respir Med. 2008; 102:1329-34.

16. Newcomb AE, Clarke CP. Spontaneous pneumomediastinum: a benign curiosity or a significant problem? Chest. 2005; 128:3298-302. 